\title{
Metallopolymer Nanocomposites Based on PP/Ni: Structure and Electrophysical Properties
}

\author{
M.A. Ramazanov*, F.V. Hajiyeva \\ Baku State University, Z. Khalilov Street 23, Baku, AZ1148, Azerbaijan \\ (Received May 20, 2019; revised version July 26, 2019; in final form August 20, 2019)
}

\begin{abstract}
The polymer nanocomposite structures based on isotactic polypropylene and nickel nanoparticles were obtained and studied by scanning electron microscopy, UV-Vis, FT-IR, and dielectric spectroscopy. IR studies show that the introduction of nickel nanoparticles into the polypropylene matrix does not change the chemical structure of the polymer, that is, nickel nanoparticles are not in the chemical, but in physical interaction with the polymer. It is also shown that as the frequency increases, the value of the permittivity of the nanocomposite based on $\mathrm{PP} / \mathrm{Ni}$ does not change, and this is due to the lack of polarization processes. The value of the dielectric loss tangent depends on the $\mathrm{Ni}$ concentration with an extremum, that is, with an increase in the content of Ni nanoparticles, the value of the dielectric loss tangent decreases and at a content of $3 \% \mathrm{Ni}$ in the polymer, the value of $\tan \delta$ is minimal and a further increase in the concentration leads to an increase in the dielectric loss tangent. A sharp decrease in the resistivity at $383 \mathrm{~K}, 413 \mathrm{~K}$, and $423 \mathrm{~K}$, respectively, for the nanocomposites $\mathrm{PP} / 3 \% \mathrm{Ni}, \mathrm{PP} / 5 \% \mathrm{Ni}$, and $\mathrm{PP} / 10 \% \mathrm{Ni}$ is explained by the destruction of the crystalline phase of the polymer and the increase in electrical conductivity of the nanocomposites.
\end{abstract}

DOI: 10.12693/APhysPolA.136.513

PACS/topics: nanoparticles, nanocomposites, polypropylene, nickel

\section{Introduction}

At present, the modification of polymers is one of the main methods for controlling the properties of various thermoplastics and elastomers. One of the most promising methods for modifying polymers is the introduction of nanoparticles, and in particular metal ones. At the same time, it is possible to combine the unique properties of metal-containing nanoparticles and an organic polymer matrix $[1,2]$. The use of nanoparticles of metals of variable valency as a filler in elastomeric compositions makes it possible to obtain fundamentally new materials with a spectrum of unusual mechanical and physical properties. Nanodisperse metal fillers improve the thermal and electrical conductivity, magnetic susceptibility, heat capacity, and other properties of polymeric materials. Metal-containing nanoparticles have significantly high surface energy and sufficiently high chemical activity. This is due to the large proportion of surface atoms compared to the total number of atoms in the volume of the particle. High surface energy of nanoobjects leads to the appearance of unusual surface properties and reactions. Therefore, one of the problems in the development of polymeric nanocomposites is efficient dispersion and stabilization of nanoparticles in the matrix of the material [3-6]. A technology for the preparation and molding of the above materials has been developed and is constantly improving, and their mechanical and electrophysical properties are investigated. An analysis of the conducted studies

*corresponding author; e-mail: r50@mail.ru shows the prospects of using such nanocomposite materials in acoustics for creating various waveguide structures. This is due to their low acoustic impedance and low dielectric constant. The change of the concentration of metal filler in the polymer matrix significantly affects the main parameters of the nanocomposite like mediumelectrical conductivity, complex dielectric permittivity, plasma frequency, etc. Thus, by choosing the composition of the nanocomposite-dielectric polymer matrix, the type of metal, the size of the metallic nanoparticles, and their concentration in the matrix, it is possible to control the basic physical properties of the mediumelectrical, optical, galvanomagnetic, etc. [7-10].

Polypropylene (PP) at the present time is one of the most prevalent synthetic thermoplastic polymer that is widely applied in many fields. Introduction of nanosized inorganic particles in polymer allows to design the structure of material by means of transfer of plain volume filled system to the system with given supramolecular architecture and spatial distribution of the filler, that promotes the creation of the polymer with new technological and operating properties. [11]. Modification of PP leads to creating a variety of composite materials and allows to solve the problem of obtaining materials with desired properties and expand the area of their use. Among metal nanoparticles, nickel $(\mathrm{Ni})$ nanoparticles are of great interest in the modern materials world due to special electronic, optical, and magnetic properties and its wide variety of applications in catalysis, conducting inks, multi-layered ceramic capacitors, microelectronics, thick-film electrode material, and solar-cells $[12,13]$. The nanocomposite on the basis of PP polymer and $\mathrm{Ni}$ nanoparticles is a matter of indubitable interest for 
targeting the design of new nanocomposite materials. So, the study of the dependence of properties of nanocomposite on the characteristics of its individual components can lead to the preparation of nanocomposite with set of practically important properties.

Pascariu et al. have investigated of polythiophenenickel (PT-Ni) nanocomposites using electrochemical oxidative polymerization of thiophene in the presence of nickel nanoparticles. They have proved that the electrical conductivity of the composites increased from $4.5 \times 10^{-3} \mathrm{~cm}^{-1}$ to $1.25 \times 10^{-2} \mathrm{~cm}^{-1}$ as the amount of nickel was increased from $0.43 \%$ up to $1.3 \%$ and polythiophene-Ni nanocomposites exhibiting a good electrical conductivity response [14]. Ganga Raju Achary et al. have reported of study of electrical properties of nickel doped polyurethane nanocomposites. They have shown that the electrical properties of pure polyurethane have drastically changed due to addition of nickel nanoparticles in the polymer. The increasing tendency of ac conductivity and high tangent loss make nickel-polyurethane nanocomposites as smart materials and very useful for energy storage, biomaterials, and shape memory [15]. Goswami et al. have been prepared polyaniline-nickel nanocomposites at room temperature by in-situ polymerization of aniline in the presence of $\mathrm{Ni}$ nanoparticles. It has been established that the incorporation of $\mathrm{Ni}$ nanoparticles in polyaniline enhance the photoluminescence emission of polymer nanocomposites and occurrence of red shift [16].

In this paper we report the synthesis of monodisperse nickel nanoparticles in the presence of surfactantcetyltrimethylammonium bromide by borohydride reduction method. Next, the $\mathrm{PP}+\mathrm{Ni}$ based polymer nanocomposites have been prepared using solution casting ex-citu method. The structure of nanocomposite materials were characterized by scanning electron microscopy, UV-Vis, FT-IR spectroscopy and energydispersive analysis (EDS). Electrophysical properties of metal/polymer nanocomposites based on polypropylene and nickel nanoparticles are studied.

\section{Experimental part}

\subsection{Materials}

Nickel sulphate heptahydrate $\left(\mathrm{NiSO}_{4} \cdot 7 \mathrm{H}_{2} \mathrm{O}\right.$, 98\% chemically pure, PLC); sodium tetrahydroborate $\left(\mathrm{NaBH}_{4}, 632287\right.$ Aldrich); cetyltrimethylammonium bromide $\left(\mathrm{C}_{19} \mathrm{H}_{42} \mathrm{BrN}\right.$, AB $117004,98 \%$ chemically pure); isotactic polypropylene (PP brand Sigma Aldrich Pcode 1001326963); toluene (PLC 141745); deionized water.

\subsection{Synthesis of magnetic nanoparticles of nickel and nanocomposites based on $\mathrm{PP} / \mathrm{Ni}$}

To synthesize magnetic nickel nanoparticles $30 \mathrm{ml}$ of $0.5 \%$ cetyltrimethylammonium bromide solution was added to $100 \mathrm{ml}$ of $0.1 \mathrm{M} \mathrm{NiSO}_{4}$ solution. The mixture was vigorously blended on a magnetic stirrer at room temperature for $30 \mathrm{~min}$. Then, a $0.1 \mathrm{M}$ solution of $\mathrm{NaBH}_{4}$ with a rapid jet was added to the initial mixture. The solution sharply turned black, which indicated the formation of nickel nanoparticles. The mixture was intensively mixed for another 20 min with a magnetic stirrer. The black precipitate was separated from the solution by decantation and washed several times with distilled water to remove extraneous ions salts. The colloidal nickel solution was also subjected to ultrasonic treatment for $10 \mathrm{~min}$ on an ultrasoundifier VSX 500 2008. The colloidal solution of nickel was transferred to a Petri dish and dried in an air for $24 \mathrm{~h}$ [16]. The reaction and the scheme for the formation of nickel nanoparticles can be shown by the following reaction:

$$
\begin{aligned}
& \mathrm{NiSO}_{4}+2 \mathrm{NaBH}_{4}+6 \mathrm{H}_{2} \mathrm{O} \rightarrow \mathrm{Ni}^{0}+\mathrm{Na}_{2} \mathrm{SO}_{4} \\
& \quad+2 \mathrm{~B}(\mathrm{OH})_{3}+4 \mathrm{H}_{2} \uparrow
\end{aligned}
$$

Polymeric nanocomposite materials were prepared by solution casting ex-citu method as follows: isotactic polypropylene was dissolved in toluene at a temperature of $120^{\circ} \mathrm{C}$. Nickel nanoparticles were added to the polymer solution at various weight contents of nickel and were mixed for an hour until a homogeneous mixture was obtained. The mixture was transferred to a Petri dish and dried in a vacuum oven during the day. Then, thin films of nanocomposites were obtained from these samples by hot pressing method at a meltingtemperature of polypropylene and a pressure of $10 \mathrm{MPa}$. Cooling of the films after hot pressing was carried out in water and the cooling rate of nanocomposite films was $200 \mathrm{deg} / \mathrm{min}$.

\subsection{Characterization}

\subsubsection{XRD analysis}

$\mathrm{X}$-ray diffraction analysis was performed with Rigaku Mini Flex 600 XRD diffractometer at ambient temperature. In all the experiments, $\mathrm{CuK}_{\alpha}$ radiation operating at $15 \mathrm{~mA}$ and $30 \mathrm{kV}$ was used. The samples were scanned in the $20-70^{\circ} \mathrm{C}$ range of Bragg angle $2 \theta$.

\subsubsection{SEM analysis}

Scanning electron microscopy (SEM) and energydispersive spectrum analysis of nanocomposite samples were taken with Scanning Electron Microscope JEOL JSM-7600F at an accelerating voltage of $15.0 \mathrm{kV}$, SEI and COMPO regimes. Energy dispersive micro-X-ray analysis (EDS) was performed using the device X-Max50 (Oxford Instruments). To eliminate the charge excess from the surface of polymeric nanocomposite, it was covered with a platinum layer of $10 \mathrm{~nm}$ thickness.

\subsubsection{Infrared spectroscopy (FT-IR) and UV-Vis spectroscopy analysis.}

Polymer nanocomposite structure was studied by IR spectroscopy (spectrometer Varian 3600 FT-IR) at 4000-400 $\mathrm{cm}^{-1}$ at room temperature. The UV spectra have been recorded on Spectrophotometer Specord 250 Plus at $200-700 \mathrm{~nm}$ and at ambient temperature. 


\subsubsection{AFM analysis}

The morphology of samples was studied by using Integra-Prima (NT-MDT, Zelenograd). A special silicon cantilever, prepared by plasma chemical method of etching with radius of curvature of needle $20 \mathrm{~nm}$ and resonance frequency $1-5 \mathrm{~Hz}$ was used. The measurements were performed in tapping microscopy mode in air, the changes in the oscillation amplitude of the cantilever needle that defines the surface topography was recorded. The scanning rate and scanning lines number on the image are $1.969 \mathrm{~Hz}$ and $256 \mathrm{~Hz}$, respectively.

\subsubsection{Dielectric spectroscopy}

Measurement of the dielectric permittivity, dielectric loss tangent and resistivity nanocomposites conducted using immittance meter MNIPI E7-20 by applying a broadband meter E7-20 immittance measured the frequency dependence of capacitance and dielectric loss at a temperature $T=293 \mathrm{~K}$ in the frequency range $f=25-10^{6} \mathrm{~Hz}$. Measurement of dielectric permittivity versus temperature was carried out at $f=1 \mathrm{kHz}$ using MNIPI meter E7-21. Measurement of specific resistance value depending on temperature was controlled by teraommeter E7-13 A.

\section{Results and discussion}

Figure 1 shows the diffraction pattern of nanoparticles of Ni. The diffraction pattern exhibited three distinctive peaks for $2 \theta$ at $44.4 \circ, 51.7 \circ$, and $76.3 \circ$, which can be indexed to the (111), (200), and (220) reflections of fcc nickel according to the ICDD map (PDF-2/Release 2011 RDB) 01-078-7533[16]. Figure 2 shows SEM images of nickel nanoparticles stabilized in the presence of CTAB. As can be seen, from SEM images, the average size of nickel nanoparticles is $6-13 \mathrm{~nm}$. Figure 3 shows the energy-dispersive spectrum of nanoparticles and it is established that the synthesized nanoparticles belong to nickel nanoparticles. Figure 4 shows the AFM 2D and 3D images of nickel nanoparticles. Scanning was carried out at $900 \times 900 \mathrm{~nm}^{2}$. AFM results show that the average size of nickel nanoparticles is $18-20 \mathrm{~nm}$. As can be seen, SEM and AFM studies correlate well with each other.

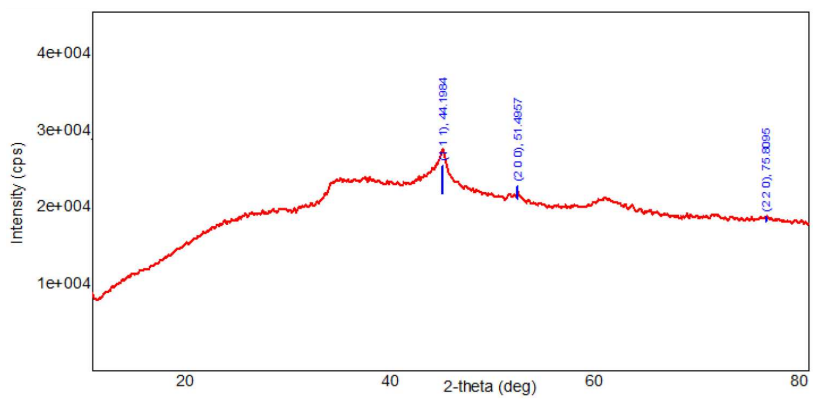

Fig. 1. Diffraction pattern of nickel nanoparticles.
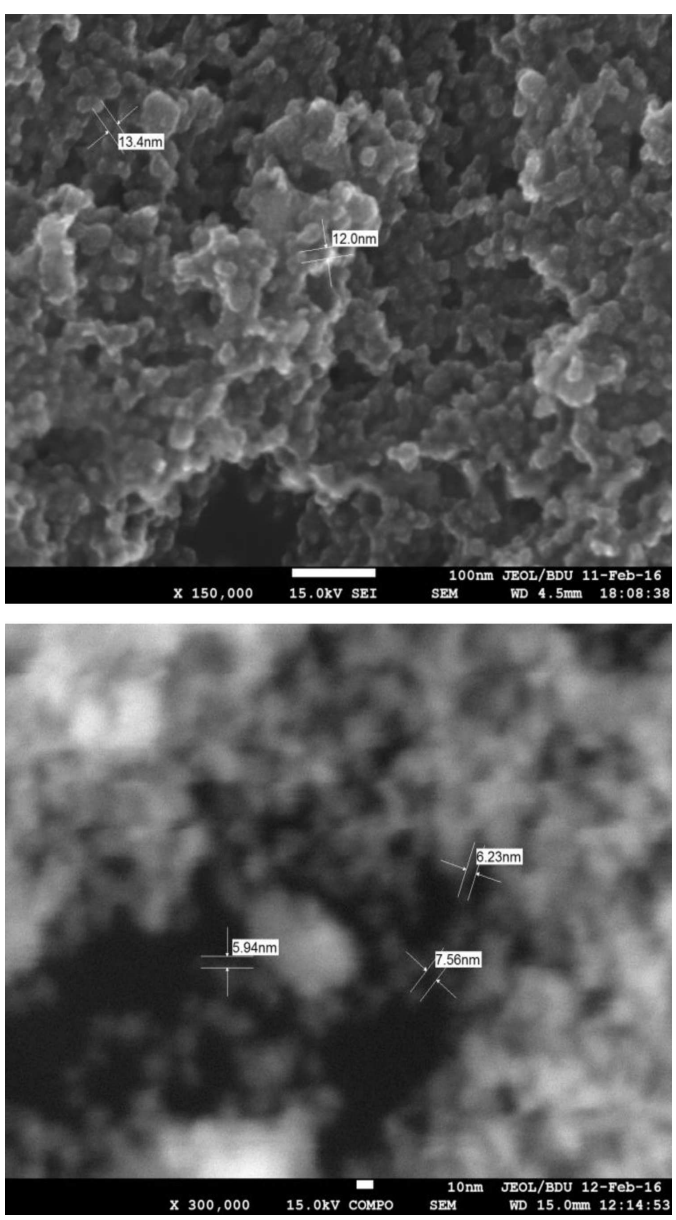

Fig. 2. SEM image of $\mathrm{Ni}$ nanoparticles stabilized in the presence of CTAB.

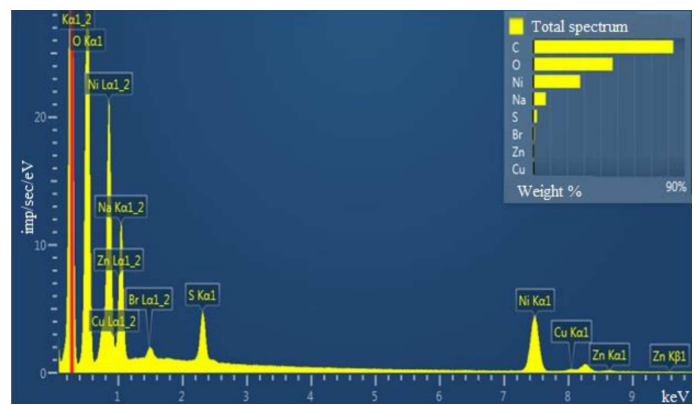

Fig. 3. Energy-dispersion spectrum of nickel nanoparticles.

Figure 5 shows IR spectra of $\mathrm{PP}$ and nanocomposites based on $\mathrm{PP} / \mathrm{Ni}$. IR study of nanocomposites shows that with introduction of $\mathrm{Ni}$ nanoparticles into the PP matrix, the intensity of the absorption bands at $2838 \mathrm{~cm}^{-1}, 2722 \mathrm{~cm}^{-1}, 2616 \mathrm{~cm}^{-1}$, $2581 \mathrm{~cm}^{-1}, \quad 2256 \mathrm{~cm}^{-1}, 2173 \mathrm{~cm}^{-1}, \quad 1255 \mathrm{~cm}^{-1}$, $1219 \mathrm{~cm}^{-1}, 1102 \mathrm{~cm}^{-1}, 1166 \mathrm{~cm}^{-1}, 1044 \mathrm{~cm}^{-1}$, $998 \mathrm{~cm}^{-1}, 973 \mathrm{~cm}^{-1}, 899 \mathrm{~cm}^{-1}, 809 \mathrm{~cm}^{-1}$ decreases, and the band intensity at $1378 \mathrm{~cm}^{-1}$ is increased. 

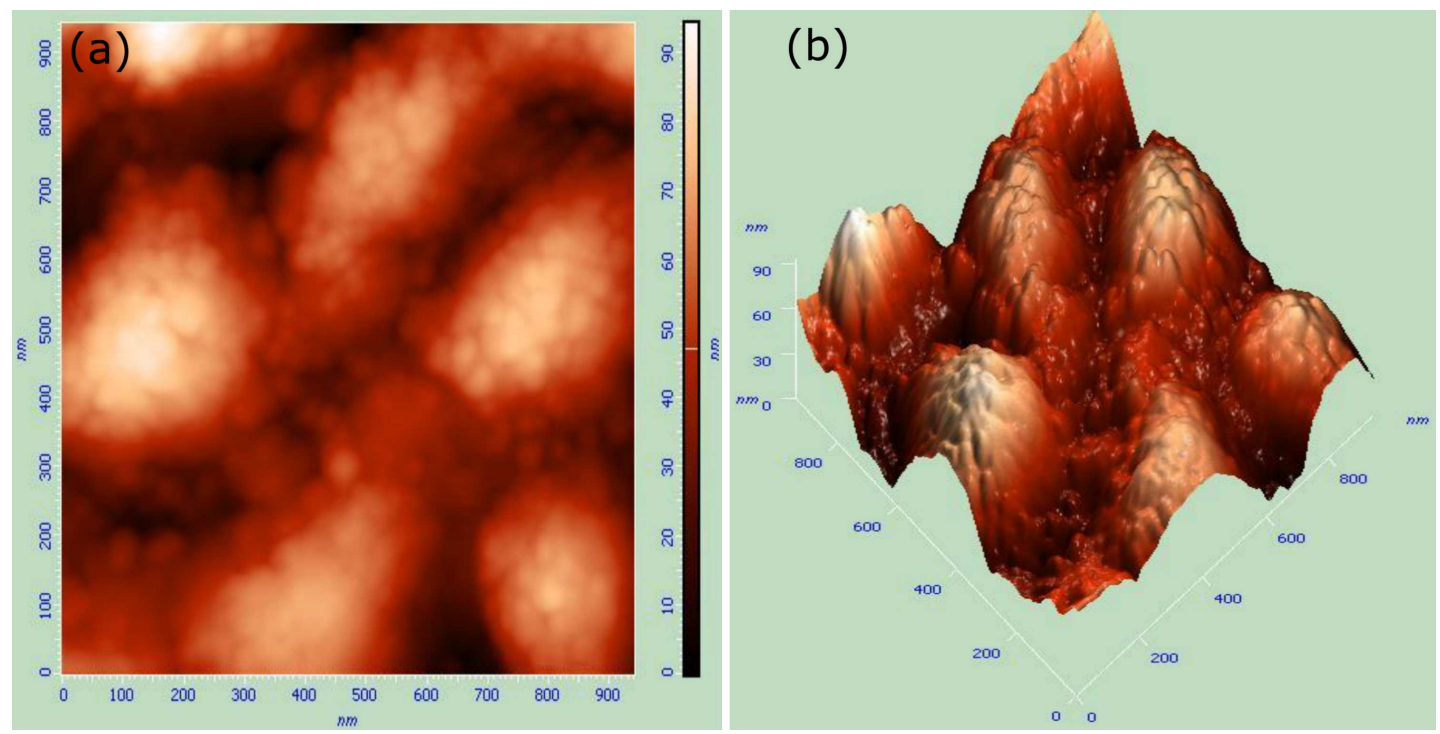

Fig. 4. AFM 2D and 3D image of the surface of Ni nanoparticle.
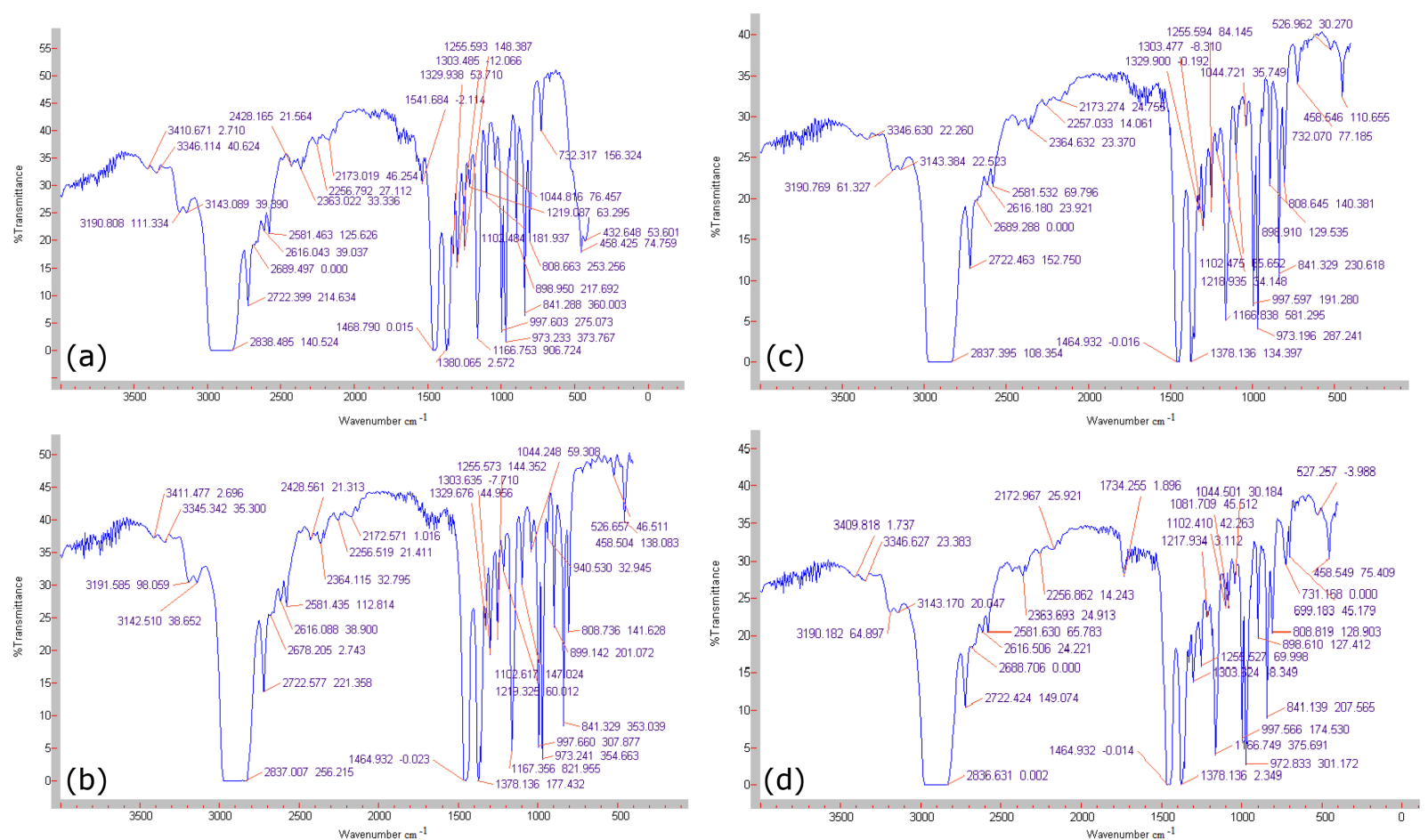

Fig. 5. IR spectra of (a) PP, (b) PP $/ 1 \% \mathrm{Ni}$, (c) $\mathrm{PP} / 3 \%$, (d) $\mathrm{PP} / 5 \% \mathrm{Ni}$.

The absorption band at $2838 \mathrm{~cm}^{-1}$ corresponds to $\mathrm{CH}_{2}$-stretching vibrations; $1378 \mathrm{~cm}^{-1}$ corresponds to the symmetric deformation vibrations of the $\mathrm{CH}_{3}-$ group. The region $1200-1370 \mathrm{~cm}^{-1}$ belong to fan and torsional vibrations of $\mathrm{CH}_{2}$ - groups and deformation vibration of $\mathrm{CH}$-group, which strongly interact with each other. The absorption band in the region $700-1200 \mathrm{~cm}^{-1}$ is caused by the interaction of pendulum vibration of $\mathrm{CH}_{2}-$ and $\mathrm{CH}_{3}-$ groups with stretching vibrations of the carbon skeleton. The absorption bands in the region of $500-150 \mathrm{~cm}^{-1}$ refer to the deformation vibrations of the skeleton and to the internal rotations of the chain. These vibrations are not localized in one monomer unit and, therefore, the corresponding bands clearly appear only in the presence of a highly organized spiral structure. 
As can be seen from the IR spectra, the introduction of Ni nanoparticles into the PP matrix does not change the chemical structure of the polymer, that is, nickel nanoparticles are not in the chemical, but in the physical interaction with the polymer. Figure 6 gives the absorption spectra for nanocomposites based on $\mathrm{PP} / \mathrm{Ni}$. A wide peak at the range of $270-350 \mathrm{~nm}$ belongs to the metallic nature of nickel [17].

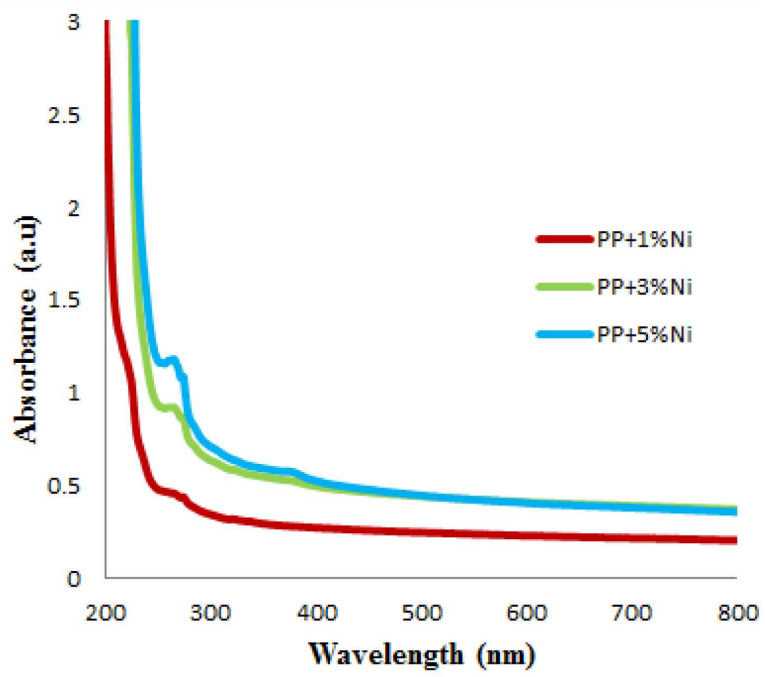

Fig. 6. UV-Vis absorption spectra for nanocomposites based on $\mathrm{PP} / \mathrm{Ni}$.

Figure 7 shows SEM images of polymeric nanocomposites based on $\mathrm{PP} / \mathrm{Ni}$ with $5 \%$ and $10 \%$ mass content of nickel nanoparticles. As can be seen from the figure, the average size of nickel nanoparticles in the polymer matrix of PP at a $5 \% \mathrm{Ni}$ content is $9-11 \mathrm{~nm}$, with a $10 \%$ content of $11-19 \mathrm{~nm}$.

The dependence of the dielectric permittivity of PP and nanocomposites on the base of $\mathrm{PP} / \mathrm{Ni}$ on the frequency was studied. Figure 8 shows the dependency of the dielectric permittivity of nanocomposites on frequency. As can be seen from Fig. 8 with the addition of nickel nanoparticles to the dielectric matrix of polypropylene, the dielectric permittivity of nanocomposites increases to $3 \%$ of the volume content, and then a decrease is observed. It is assumed that up to $3 \%$ mass content nickel nanoparticles play the role of the centre of the structurant in the matrix, and with increasing nanoparticle concentration $\mathrm{Ni}$ behaves as a filler. It is established that, with increasing filler concentration, the conductivity of the nanocomposite increases and these results correlate well with the results of decreasing the dielectric permittivity of the nanocomposite with an increase in the concentration of nanoparticles. It is also shown that, with increasing of nickel concentration, the bulk density of defects in the polymer matrix increases. It is also clear from Fig. 8 that the value of the permittivity does not change with increasing frequency. In our opinion, this is due to the fact
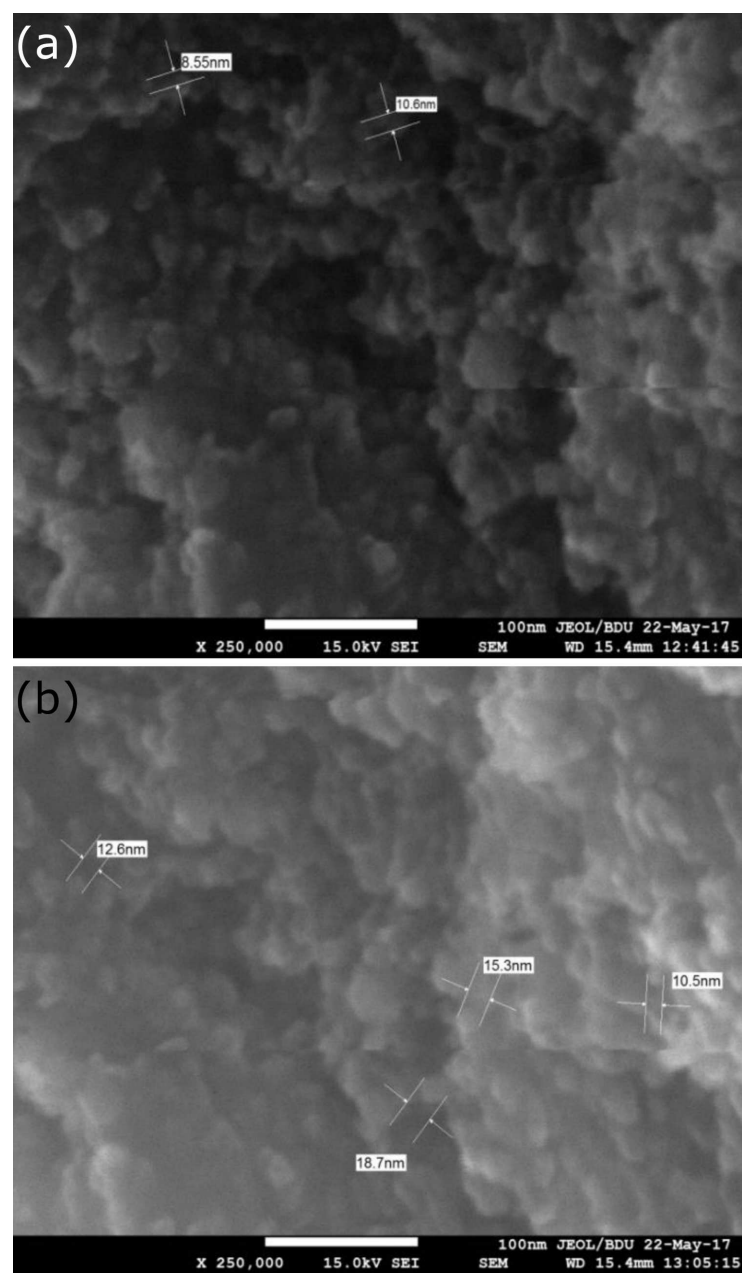

Fig. 7. SEM images of polymer nanocomposites based on $\mathrm{PP} / \mathrm{Ni}$ : (a) $\mathrm{PP} / 5 \% \mathrm{Ni}$, (b) $\mathrm{PP} / 10 \% \mathrm{Ni}$.

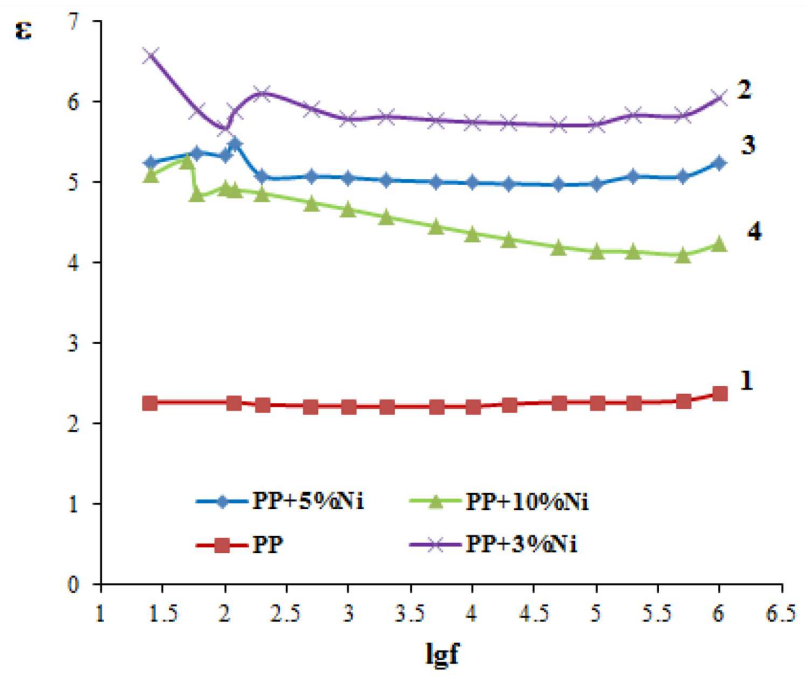

Fig. 8. Dependence of dielectric permittivity of PP and nanocomposites based on $\mathrm{PP} / \mathrm{Ni}$ on frequency: 1. $\mathrm{PP} ; 2$. $\mathrm{PP} / 3 \% \mathrm{Ni} ; 3$. $\mathrm{PP} / 5 \% \mathrm{Ni} ; 4$. $\mathrm{PP} / 10 \% \mathrm{Ni}$. 
that in this case there are practically no polarization processes, i.e. with a further increase in the concentration, the nanoparticles behave as a separate dispersed phase, and consequently, as the concentration of nanoparticles increases, the conductivity of the compositions increases [18-21].

It is also shown that the value of the dielectric loss tangent depends on the $\mathrm{Ni}$ concentration with an extremum, that is, with an increase in the content of Ni nanoparticles, the value of the dielectric loss tangent decreases and at a content of $3 \% \mathrm{Ni}$ in the polymer, the value of $\tan \delta$ is minimal and a further increase in concentration leads to an increase in the values of the dielectric loss tangent (Fig. 9). The increase in dielectric losses means an increase in the relaxation processes, that is, due to an increase in $\tan \delta$, the conductivity in nanocomposites at a $3 \% \mathrm{Ni}$ content is minimal. This result correlates well with the increase in the dielectric permittivity. It is shown that the value of the permittivity decreases with increasing temperature. The decrease in the permittivity as a function of temperature is associated with an increase in the conductivity of nanocomposites (Fig. 10).

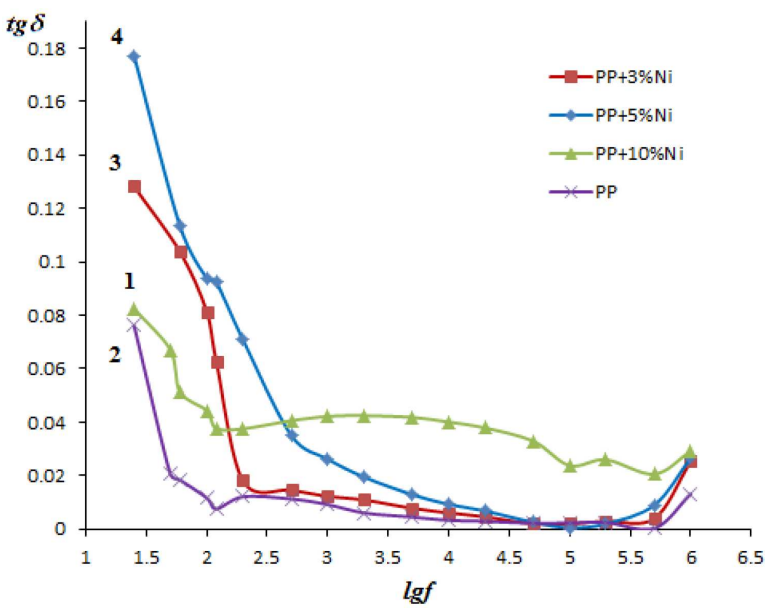

Fig. 9. Dependence of the tangent of the dielectric losses of $\mathrm{PP}$ and nanocomposites based on $\mathrm{PP} / \mathrm{Ni}$ on the frequency: 1. PP; 2 . PP $/ 3 \% \mathrm{Ni} ; 3$. PP $/ 5 \% \mathrm{Ni}$; 4. $\mathrm{PP} / 10 \% \mathrm{Ni}$.

Figure 11 shows the dependence of the resistivity of nanocomposites based on $\mathrm{PP} / \mathrm{Ni}$ on the temperature. As can be seen from the figure, as the temperature increases, the value of the resistivity first decreases for nanocomposites $\mathrm{PP} / 3 \% \mathrm{Ni}$ up to $383 \mathrm{~K}$; for nanocomposites based on $\mathrm{PP} / 5 \% \mathrm{Ni}$ up to $413 \mathrm{~K}$, for nanocomposites based on $\mathrm{PP} / 10 \% \mathrm{Ni}$ up to $423 \mathrm{~K}$. Then, the value of the resistivity begins to increase. The decrease in the resistivity to $383 \mathrm{~K}, 413 \mathrm{~K}$, and $423 \mathrm{~K}$, respectively, for $\mathrm{PP} / 3 \% \mathrm{Ni}, \mathrm{PP} / 5 \% \mathrm{Ni}$, and $\mathrm{PP} / 10 \% \mathrm{Ni}$ nanocomposites is associated with bulk polymer expansion in which the distance between particles is increased. The increase in conductivity at high temperatures is explained with increasing volumetric electrical conductivity of nanocomposites [22-24].

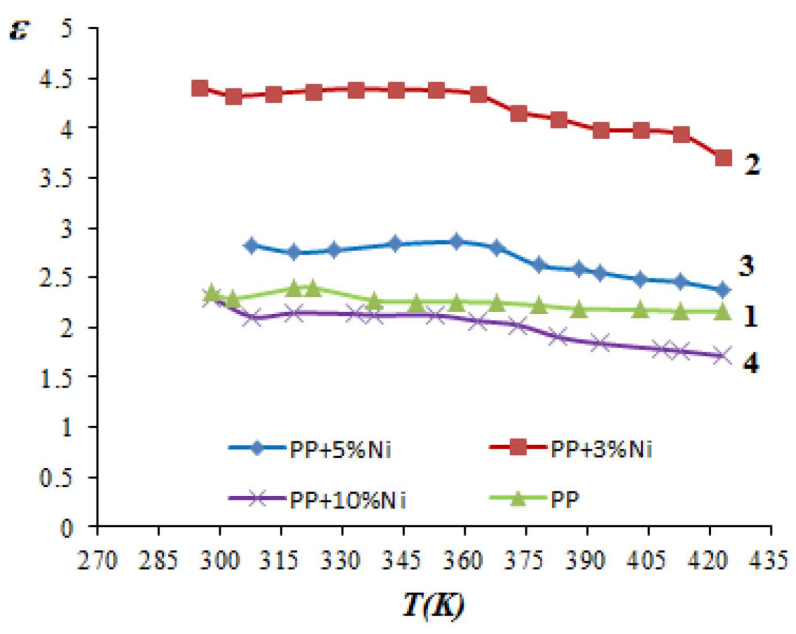

Fig. 10. Dependence of dielectric permittivity of PP and nanocomposites based on $\mathrm{PP} / \mathrm{Ni}$ on temperature: 1. PP; 2. PP $/ 3 \% \mathrm{Ni} ; 3$. PP $/ 5 \% \mathrm{Ni} ; 4$. PP $/ 10 \% \mathrm{Ni}$.

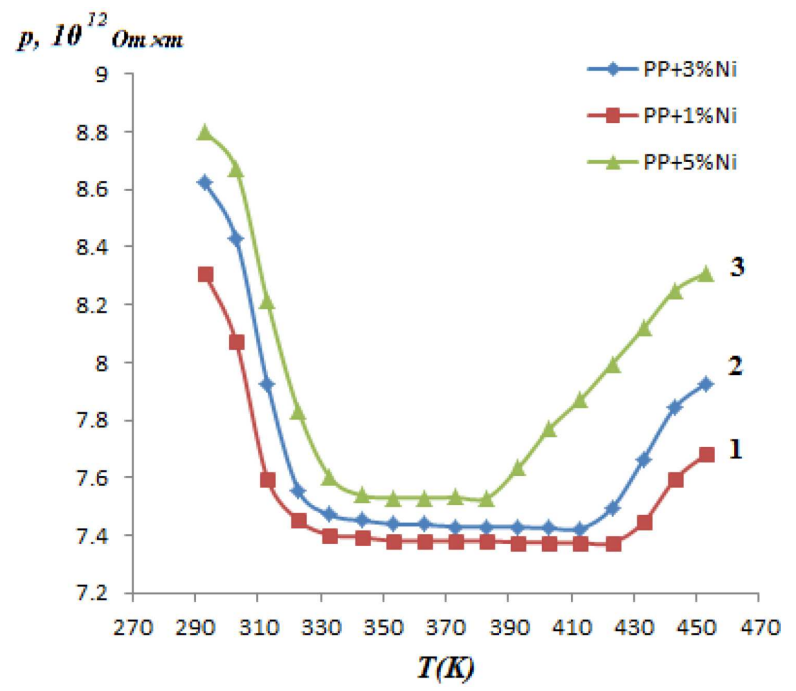

Fig. 11. Dependence of the resistivity of nanocomposites based on $\mathrm{PP} / \mathrm{Ni}$ on temperature: $1 . \mathrm{PP} / 1 \% \mathrm{Ni}$; 2. $\mathrm{PP} / 3 \% \mathrm{Ni} ; 3$. $\mathrm{PP} / 5 \% \mathrm{Ni}$.

\section{Conclusion}

In this paper new nanocomposite structures based on isotactic polypropylene and nickel nanoparticles were obtained and nanocomposites were studied by scanning electron microscopy, UV-Vis, FT-IR, and dielectric spectroscopy. IR studies show that the introduction of nickel nanoparticles into the polypropylene matrix does not change the chemical structure of the polymer, that is, nickel nanoparticles are not in the chemical, but in physical interaction with the polymer. It is also shown that as the frequency increases, the value of the permittivity of the nanocomposite based on $\mathrm{PP} / \mathrm{Ni}$ is not varied, 
and this is due to the lack of polarization processes. The value of the dielectric loss tangent as a function of the $\mathrm{Ni}$ concentration varies with the extremum, that is, with an increase in the content of $\mathrm{Ni}$ nanoparticles, the value of the tangent of the dielectric loss angle decreases. For nanocomposite on the base of $\mathrm{PP} / 3 \% \mathrm{Ni}$ the value of $\tan \delta$ is minimal and a further increase in the concentration of nanoparticles leads to an increase in the dielectric loss tangent. The decrease in the resistivity to $383 \mathrm{~K}, 413 \mathrm{~K}$, and $423 \mathrm{~K}$, respectively, for $\mathrm{PP} / 3 \% \mathrm{Ni}, \mathrm{PP} / 5 \% \mathrm{Ni}$, and $\mathrm{PP} / 10 \% \mathrm{Ni}$ nanocomposites is associated with bulk polymer expansion in which the distance between particles is increased. The increase in conductivity at high temperatures is explained with increasing volumetric electrical conductivity of nanocomposites.

\section{References}

[1] H. Zois, L. Apekis, Y.P. Mamunya, J. Appl. Polym. Sci. 88, 3013 (2003).

[2] Y. Dang, Y. Wang, Y. Deng, M. Li, Y. Zhang, Z.W. Zhang, Prog. Nat. Sci. Mater. Int. 21, 216 (2011).

[3] L. Zhang, X. Shan, P. Bass, Y. Tong, T.D. Rolin, C.W. Hill, J.C. Brewer, D.S. Tucker, Z.Y. Cheng, Sci. Rep. 6, 35763 (2016).

[4] L. Zhang, W. Wang, X. Wang, P. Bass, Z.Y. Cheng, Appl. Phys. Lett. 103, 232903 (2013).

[5] K. Sonoda, Y. Moriya, H. Jantunen, J. Mater. Sci. Pol. 29, 63 (2011).

[6] D.H. Im, E.S. Kim, J. Ferroelectrics 434, 19 (2012).

[7] A. Qureshi, A. Mergen, M.S. Eroğlu, N.L. Singh, A. Güllüoğlu, J. Macromol Sci. A 45462 (2008).

[8] K. Prashanthaa, J. Soulestina, M.F. Lacrampea P. Krawczaka, G. Dupinc, M. Claes, A. Tewarid, Polym. Composites 18, 489 (2010).
[9] C. Kale, P. Dhoka, R.K. Goyal, J. Electron. Mater. 45, 4148 (2016)

[10] V.V. Tchmyreva, A.T. Ponomarenko, E-Polymers 3 (1), (2003).

[11] A. Maharramov, M. Ramazanov, F. Hajiyeva, H. Shirinova, U. Hasanova, Chem. Eng. Trans. 60, 55 (2017)

[12] M. Abdo Mohd, E. Gharibshahi, N. Soltani, M.M. Yunus, E. Saion, J. Polym. 6, 2435 (2014).

[13] S. Schrittwieser, D. Reichinger, J. Schotter, J. Mater. 11, (2018).

[14] P. Pascariu, A. Airinei, M. Grigoras, L. Vacareanu, F. Iacomi, J. Appl. Surf. Sci. 352, 95 (2015).

[15] Ganga Raju Munisha B, D.S. Singh, K.S. Parida, Polym. Sci. 4, 2471 (2018).

[16] M. Goswami, R. Ghosh, K. Meikap, J. Adv. Sci. Lett. 22, 229 (2016).

[17] S.C. Kumar, P.K. Tomar, J. Saudi Chem. Soc. 18 , 437 (2014).

[18] A.M. Maharramov, M.A. Ramazanov, L.D. Palma, H.A. Shirinova, F.V. Hajiyeva, Russian Physics Journal 60, 1572 (2018).

[19] A.M. Magerramov, M.A. Ramazanov, F.V. Hajiyeva, Surf. Eng. Appl. Electrochem. 49, 355 (2013).

[20] M.A. Ramazanov, A.M. Maharramov, H.A. Shirinova, L.D. Palma, J. Thermoplast. Compos. Mater. 2018, 089270571879654 (2018).

[21] M.A. Ramazanov, A.R. Imamaliyev, S.A. Humbatov, Z.A. Agamaliev, Russ. Phys. J. 60, 1659 (2017).

[22] S.M. Mammadov, R.F. Khankishiyeva, M.A. Ramazanov, O.H. Akbarov, E.O. Akbarov, H.N. Akhundzada, Am. J. Polym. Sci. 7, 23 (2017).

[23] M.A. Ramazanov, K.S. Ibragimova, S.A. Abasov, Surf. Eng. Appl. Electrochem. 48, 380 (2012).

[24] M.A. Ramazanov, F.V. Hajiyeva, A.M. Maharramov, J. Integr. Ferroelectr. 192, 103 (2019). 